\title{
USING THE ANALYTICAL PART OF CRM IN SMALL AND MEDIUM-SIZED ENTERPRISES IN THE CZECH REPUBLIC
}

\author{
Langerová, A., Starzyczná, H., Zapletalová, š.
}

Adéla Langerová / Silesian University, School of Business Administration in Karvina, Department of Business Economics and Management, Univerzitni nam. 1934/3 73340 Karvina, Czech Republic. Email: chromcakova@opf.slu.cz

Halina Starzyczná / Silesian University, School of Business Administration in Karvina, Department of Business Economics and Management, Univerzitni nam. 1934/3 73340 Karvina, Czech Republic. Email: starzyczna@opf.slu.cz

Šárka Zapletalová / Silesian University, School of Business Administration in Karvina, Department of Business Economics and Management, Univerzitni nam. 1934/3 73340 Karvina, Czech Republic. Email: zapletalova@opf.slu.cz

\section{Abstract}

The article aims to evaluate the level of the analytical part of CRM in SMEs in Czechia and its impact on increasing the companies' profitability. In the empirical part, primary quantitative research was carried out. The subject of quantitative research was selected for analytical activities. The object of the research was SMEs in the Moravian-Silesian Region. The questionnaire survey was attended by 1067 respondents. To evaluate the level of the utilisation of selected analytical activities, the PDCA method (Deming cycle), which is used to evaluate process quality, was modified. The choice of this method was inspired by the Anglo-Australian approach to the evaluation of relationship marketing based on quality management. The starting point for the application of the PDCA method was the mode. This article provides a different perspective on CRM level assessment. A research question addressed the level of analytical activities performed. This approach highlighted the highest level in the evaluation of sales, customer satisfaction analysis, and customer segmentation, which are basic marketing activities. CRM cannot work without these activities. The lowest level was reflected in customer churn prediction and in setting up a method of measuring customer loyalty. Building long-term relationships are the main CRM goal, which should contribute to improving the economic results of companies. Therefore, five hypotheses were formulated, expressing the relationship between the level of selected analytical activities and the increasing profitability of the companies. The hypotheses were verified by regression analysis. All analytical activities had an impact on the profitability of companies.

Keywords: CRM; CRM architecture; analytical part of CRM; PDCA method; Czech Republic; customers; SMEs

JEL Classification: M31 


\section{Introduction}

As early as in the 1960s, the first ideas of managing customer relationships emerged. Levitt (1960) paid attention to the company's focus on customer needs. Day and Wensley (1983) later elaborated this notion and identified Customer Relationship Management (CRM) as a system that allows obtaining customer information and then using this information to create offers that better meet customers' needs than competitors. All customer information can be used in the analytical part of CRM.

Small and medium-sized enterprises (SMEs) play an essential role in the economy of many developed countries and the Czech Republic. The position of SMEs is not simple on the market. Current development trends such as the concentration and market dominance of large enterprises, accompanied by market globalisation on the demand-supply side, endanger them in away. In a strong competitive environment that is characteristic of the globalisation process, it is imperative to acquire customers and maintain them so that this relationship would bring good economic results to the company (Starzyczná et al., 2016). CRM is a chance for SMEs to learn about the customer as much information as possible. This information is then analysed, and results used in customer relationship decisions.

The article aims to evaluate the level of the analytical part of CRM in SMEs in the Czech Republic and its impact on increasing the companies profitability. A modified PDCA method was applied to evaluate the level. The starting point is a brief theoretical discussion of the examined issues. It follows up with the methodology of processing primary quantitative research focused on individual selected analytical activities implemented within the CRM architecture along with the presentation of results. A research question and five hypotheses have been formulated based on the current state of knowledge. The regression analysis has been applied to hypotheses verification.

\section{Literature review, research question and hypotheses}

CRM has its architecture. Experts most often report three basic parts, namely the analytical, operational, and collaborative part of CRM. For instance, Dohnal (2002), Peelen (2005), Greenberg (2010) refer to this breakdown. Further research confirmed that it is also necessary to implement the strategic part (Starzyczná et al., 2007). Buttle and Maklan (2015) also deal with the strategic part. Loštáková (2017) also does not neglect strategic CRM, which is also referred to as a new approach to CRM. The strategic part focused on economic and non-economic results will not work without analytical parts providing information and documentation for decision making. The quality of analytical activities and their level affects all other parts of the CRM architecture. It should be in the interest of companies to constantly improve it.

The objective of the analytical part of CRM is to analyse customer data, evaluate, model, and predict customer behaviour (Dohnal, 2002). There are not many studies on CRM architecture. Some experts are considering an analytical CRM model that would best support business decision-making (Xie et al., 2008). Let's look at the analytical activities that are the focus of our research.

Companies collect information about customers and store it for further processing. The data obtained is evaluated and used to predict possible customer behaviour. Customer data collection is known as data mining. Using data mining, marketers can obtain information 
about individual customers, trends and segments, and the relationships between data (Kotler \& Keller, 2013). It is about working with a large amount of data, which is not so typical for SMEs. Companies store customer data that is used for a variety of analyses. Data is stored in the database and used to provide the operational part of CRM (Dohnal, 2002). It serves to identify potential customers, make decisions about the offer for customers, deepen customer loyalty, reactivate customers, and eliminate major mistakes (Kotler \& Keller, 2013).

According to Burnett (2002), the acquisition, processing, storage, and subsequent evaluation and use of customer data, all of which aim is to create added value for the customer, are a key part of analytical CRM for the enterprise. It deals with the determination of profitable customers, customer behaviour, satisfaction, and the assessment of their loyalty. The sales results and the value of an individual customer are analysed, the shopping carts are evaluated. This is related to the fact that Buttle and Maklan (2015) perceive CRM as a business strategy that focuses on acquiring and retaining profitable customers. Marketing campaigns are evaluated. Analyses are used to create backgrounds for decision-makers regarding customer behaviour responses. Companies can formulate trends in demand and create customer profiles (Godson, 2009). Based on the current state of knowledge, the following research question has been formulated:

RQ1: At what level of the modified Deming cycle are the individual activities of the analytical part of the CRM architecture in SMEs implemented?

This question will be answered during the presentation of the results and discussion. Now let's consider the activities that are in the foreground of our research.

Customer satisfaction is being addressed by many researchers. Khalafinezhad and Long (2013) deal with the influence of customer relationship management on their satisfaction and loyalty. In his publication, he presents a conceptual model that includes CRM quality criteria and, consequently, customer satisfaction and building long-term customer relationships. These include employee behaviour, service quality, relationship development, and interaction management. IT technology is often used for developing customer interactions as a means of attracting, developing, and retaining customers.

In general, satisfaction can be understood as the pleasure or frustration of the individual, which is based on a comparison of product performance and expectations (Tsiros et al., 2004). Customer satisfaction is accompanied by the satisfaction of other stakeholders, such as employees, intermediaries, suppliers, and shareholders. Companies try to get feedback from their customers and study and monitor customer satisfaction. Feedback indicates that the CRM process is not working as expected (Miklenčičová, 2012).

The implementation of customer satisfaction analysis can be reflected in the number of customers because companies can better respond to customer needs and wishes. A customer-oriented company strives to make customers satisfied. A satisfied customer repeats the purchases, affects the company profit, profitability, and other company decisions about production, an investment in research, respectively, in CRM. However, some studies suggest that perceived satisfaction may fluctuate and may not always be a guaranteed prerequisite for repeat purchases and customer loyalty (Paulsen \& Birk, 2007), yet we assume that there is a relation between the level of customer satisfaction analysis and CRM benefits. Based on the current state of knowledge, the following hypothesis can be formulated: 
Hypothesis 1: The level of implementation of customer satisfaction analysis is positively related to increasing profitability.

An important part of marketing efficiency and, therefore, CRM is the evaluation and analysis of sales. This analysis aims to evaluate the differences between actual sales and planned sales and identify the causes of possible contradiction (Jakubíková, 2013). Selected criteria include customer target groups, sales areas, distribution channels, product and service offers, sales promotion, etc. The evaluation of sales from a marketing point of view is related to the value for the customer and customer value and benefits. An important task of CRM is to create value and communicate with customers. The goal is to obtain and maintain loyalty and customer satisfaction (Chromčáková et al., 2018). Vávrová (2016) expresses a significant premise that "value for the customer conditions the amount of the customer's value to the enterprise." One of the key trends in marketing and management of the past decade was an increased customer value. Businesses strive to increase customer value by attracting new customers, retaining existing customers, reducing costs and selling their products or services to their customers (Ralston, 2003; Verhoef \& Lemon, 2013). The evaluation of sales should focus on assessing the economic effects of customer relationship management. Based on the current state of knowledge, the following hypothesis has been formulated:

Hypothesis 2: The level of sales evaluation is positively related to increasing profitability.

When evaluating sales and customer purchases, marketers can measure customer profitability not only by individual customers but also by segments or distribution channels. Companies carry out customer segmentation and identify customer preferences. (Chromčáková et al., 2018; Reicher \& Szeghegyi, 2015). Many entrepreneurs measure customer satisfaction. However, only a few entrepreneurs measure the profitability of individual customers (Niraj et al., 2001). According to Reinartz et al. (2005), the measurement, management, and maximisation of customer profitability is not an easy task. It is required that in decisions on resource allocation, the benefits and costs of marketing, sales, and customer interactions should be taken into account. A customer-oriented company should create an "image of an ideal customer."

The absence of knowledge of the customer structure and their needs will not allow to identify the image of an ideal client and consequently cannot build a real-life customer development strategy, which would bring the effects of better customer care. The customer will return to the company, affect sales and the companies' profitability. The starting point for a successful solution to this problem is certainly customer segmentation. It is also useful to create models or matrices that allocate company products to individual segments (Chen \& Popovich, 2002). The customer profiles created to consist of three categories of data, namely the identity of the customers, their characteristics, and their behaviour. Based on the current state of knowledge, the following hypothesis has been formulated:

Hypothesis 3: The level of segmentation of customers is positively related to increasing profitability.

In terms of customer relationship management, it is important to connect customer satisfaction monitoring with assessing customer loyalty and customer churn. In recent years, the digital revolution has increasingly influenced the behaviour of customers. Moving towards digital marketing and achieving a loyal customer base is a hallmark of marketing 4.0 (Kotler et al., 2016). 
Higher customer satisfaction and repeat purchases lead to longer customer relationships and loyalty. Low customer satisfaction leads to a change in supplier. The degree of loyalty depends on the competitive environment. Rai (2013) states that CRM involves primarily building long-term customer relationships, understanding their needs and responding to them through more products and services across multiple channels of communication, which is reflected in the effects of business. Based on the current state of knowledge, the following hypothesis has been formulated:

Hypothesis 4. The level of setting up a method of evaluating customer loyalty is positively related to increasing profitability.

Chen and Popovich (2002), based on experience, draw attention to the fact that obtaining a new customer is 5 to 7 times more expensive than the effort made to maintain an existing customer. Therefore, it is considered very important to keep high-profit customers in particular and build a good loyal customer base that is stable. Loyal customers are one of the best ads for companies. This helps to attract other customers who value long-term relationships and high-quality products and services. Reasons for customer churn and their causes should be the focus of businesses. The goal of the analysis is to reveal those customers who are at risk of leaving and then respond to it in marketing strategy. The benefit is also the creation of effective retention campaigns. ${ }^{1}$

Based on the current state of knowledge, the following hypothesis has been formulated:

Hypothesis 5. The level of customer churn prediction is positively related to increasing profitability.

Part of analytical activities in the area of CRM is the evaluation of marketing campaigns that require incurring certain expenses. Marketing professionals are under increasing pressure to show how marketing spending increases the value of shareholders (Doyle, 2000). Businesses should have a business model that controls how marketing spending affects what customers know, what they believe and feel, and how they behave. These interim results are usually measured by non-financial measures such as attitudes and intentions of behaviour (Rust et al., 2004).

How can CRM help SMEs? Small and medium-sized enterprises are not a homogeneous set. These include micro, small and medium-sized enterprises, which are different in the number of employees, annual turnover and assets (Starzyczná et al., 2016), but also with its organisational structure and division of labour. A strong competitive environment forces SMEs to reflect on their strategy and customer relationships. Maintaining customer relationships and building customer loyalty can have positive results. Implementation of a CRM system can provide benefits not only for companies and their customers but also for the whole society. The SME management process is generally simpler with a simple and flexible organisational structure.

Implementation of a CRM system and its architecture is not an easy process for SMEs. Some studies deal with barriers to CRM implementation in SMEs. However, we do not find too many publications or studies in the professional literature that directly deal with CRM, which is tailor-

\footnotetext{
${ }^{1}$ Analýza odchodu zákazníků. [online]. [see. 6 12. 2018]. Available at: https://acrea.cz/reseni/analyza-
} odchodu-zakazniku-ke-konkurenci-(churn).html 
made directly for SMEs and their subsegments. Most studies have confirmed similar problems faced by SMEs. Kmieciak (2010) tried to summarise the main barriers to CRM implementation and its level. He pointed to limited financial resources, time resources, human and technological resources. Also, Alshawi et al. (2011) and Loh et al. (2011) consider the lack of financial resources or limited technological knowledge of employees as a common barrier. As a barrier, there is limited knowledge of CRM and its architecture (Liagkouras \& Metaxiotis, 2014; Piskar \& Faganel, 2009). The level of analytical activities that are the basis for the strategy and other parts of CRM can be influenced by the size of enterprises and their ability to use the necessary experts for their implementation.

\section{Materials and methods}

The subject of the research was the main CRM analytical activities. The research aimed to find out at what level the addressed companies carry out selected activities. Structural equation modelling was chosen to investigate the relationships between applying CRM and companies' profitability. The conceptual model is shown in Figure 1.

\section{Figure 1 | Conceptual model}
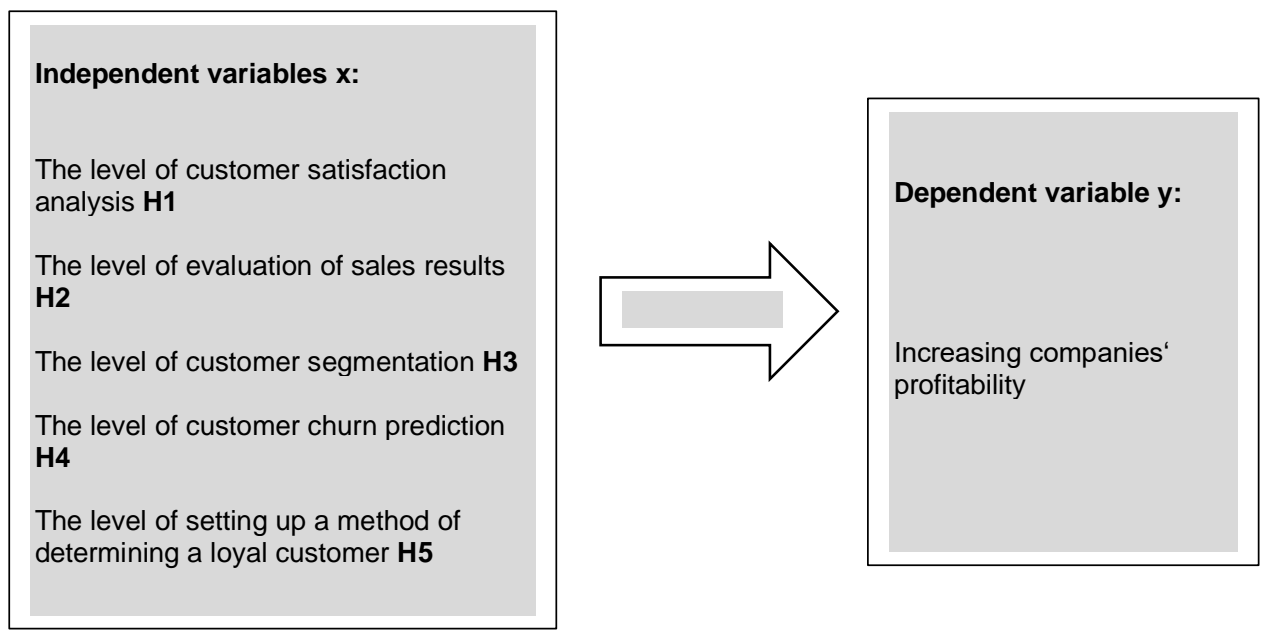

Source: authors

Five activities were evaluated for the whole sample (method WPDCA). There are more approaches to researching relationship marketing, which includes CRM. The AngloAustralian approach is based on quality management. Representatives of this approach are Christopher et al. (1991).

A special PDCA method or Deming cycle method was used to evaluate the level of analytical activities. The PDCA method is a method that is based on four essential parts aimed at improving the process or its overall change (plan; do; check; act). The practical application of the method consists of its systematic repetition to capture the level of researched activities, monitor developments, identify weaknesses in the process of CRM, and outline the direction of improvement activities. This could be a way to improve the CRM implementation process in SMEs. 
The PDCA method is also referred to as the Shewhart cycle. Shewhart (1939) discussed the concept of PDCA already in 1939 in terms of quality control. The author based on the idea that a continuous assessment of managerial practices and willingness to accept unsupported ideas could be the key to the success of the business. The method is used in enterprises even today with the aim of constantly improving the quality of products, services, applications, or processes (Gupta, 2006). This method was not found to be used to evaluate the level of CRM.

PDCA helps ensure improvement regardless of the way a company is managed. It is often very difficult to define the problem and then solve it. Nevertheless, this method provides a systematic improvement of any process. However, this cycle needs to be used consistently (Marquis, 2009). The mentioned authors deal with this method mainly in the areas of management, energy, and industry. Problems in processes and modifying the PDCA method were also dealt with by Knop and Mielczarek (2015). For the purpose of the research, the PDCA method was applied and modified. On the one hand, the individual phases of the cycle were specified, and one more option was added to the individual levels, namely the possibility of non-realisation - letter W (without realisation). This level was added to the assumption that some of the company's activities are not being implemented at all. A mode or the most frequently occurring response will be used to evaluate the use of activities in parts of the CRM architecture. Specifically, relative response rates and mode were used (the most frequent value is the value with the highest relative frequency).

After our adjustments, the individual phases of the cycle are as follows:

- W - without realisation - non-realisation of the activity,

- P - Plan - planning the intended activity (intention),

- D - Do - implementation of the activity (according to the established plan),

- C - Check -verifying the result of the implementation of the activity against the original intention,

- A - Act - modifications to the intention and to the own implementation of the activities on the basis of verification and across-the-board implementation of improvements in practice.

A survey was carried out in the Czech Republic in the period of July 2018 and February 2019 to obtain the necessary data. Descriptive and causal research was carried out. It was onetime quantitative research. The primary research was conducted electronically. The advantage was the flexibility of research. The disadvantage was that some respondents were not interested in research cooperation. Misleading information may be a risk.

The object of the research was small and medium-sized enterprises from the MoravianSilesian Region in the Czech Republic. A total of 1388 companies was contacted, while 1067 were usable and they are correctly and completely completed questionnaires were used, 321 questionnaires had to be discarded. The rate of return of the questionnaires was therefore $76.9 \%$. The respondent sample accounted for 1,067 respondents, which corresponded with the calculation of the minimum sample (Kozel et al., 2011): The minimum sample size was set at $n=384.16$. There were most micro-enterprises, namely 452 (42\%), then small enterprises in the number of 405 (38\%). There were $210(20 \%)$ medium-sized enterprises. Therefore, the basic set was represented by small, medium-sized enterprises. The basic 
sample consisted of SMEs with more than one employee in the Moravian-Silesian Region. The basic set contains most of the micro-enterprises, then small and least medium-sized enterprises. In the selected sample, these relationships also apply; however, not totally in terms of identical shares. The sample was created on a random basis. Respondents were selected on a random respondent's selection. The sample included micro-sized enterprises (up to 10 employees), small-sized enterprises (up to 50 employees), medium-sized enterprises (up to 250 employees). Dividing by a number of employees is used in EU countries. ${ }^{2}$ Other indicators are also useful for the definition of SMEs, but for our research, the number of employees was sufficient. The companies included in the study are incorporated in the Czech Republic, and all of them are private companies. There were most micro-enterprises, namely 452 (42\%), then small enterprises in the number of 405 (38\%). There were $210(20 \%)$ medium-sized enterprises. Most respondents worked in the services sector. The period of operation on the market was mostly more than ten years for almost 80 $\%$ of respondents. Most respondents are also in the $\mathrm{B} 2 \mathrm{~B}$ and $\mathrm{B} 2 \mathrm{C}$ market, so its clients were both end consumers and companies (see Table 1).

Table 1 | Structure of the respondent sample (count, \%)

\begin{tabular}{|c|c|c|c|c|c|c|c|c|}
\hline \multirow{2}{*}{$\begin{array}{c}\text { identification } \\
\text { mark }\end{array}$} & \multicolumn{2}{|c|}{ Micro } & \multicolumn{2}{|c|}{ Small } & \multicolumn{2}{|c|}{ Medium } & \multicolumn{2}{|c|}{$\Sigma$} \\
\hline & count & $\%$ & count & $\%$ & count & $\%$ & count & $\%$ \\
\hline \multicolumn{9}{|c|}{ Business sector } \\
\hline $\begin{array}{l}\text { Manufacturing } \\
\text { sector }\end{array}$ & 109 & 24 & 96 & 24 & 134 & 64 & 339 & 32 \\
\hline Trade & 123 & 27 & 139 & 34 & 32 & 15 & 294 & 27 \\
\hline Services sector & 220 & 49 & 170 & 42 & 44 & 21 & 434 & 41 \\
\hline \multicolumn{9}{|c|}{ Market orientation } \\
\hline B2B market & 154 & 34 & 185 & 46 & 53 & 25 & 392 & 37 \\
\hline B2C market & 84 & 19 & 40 & 10 & 28 & 13 & 152 & 14 \\
\hline $\mathrm{B} 2 \mathrm{~B}$ and $\mathrm{B} 2 \mathrm{C}$ & 214 & 47 & 180 & 44 & 129 & 62 & 523 & 49 \\
\hline \multicolumn{9}{|c|}{ Company age } \\
\hline $1-5$ & 37 & 8 & 35 & 9 & 0 & 0 & 72 & 7 \\
\hline $6-10$ & 65 & 14 & 77 & 19 & 15 & 7 & 157 & 15 \\
\hline $\begin{array}{c}\text { More than } 10 \\
\text { years }\end{array}$ & 350 & 78 & 293 & 72 & 195 & 93 & 838 & 78 \\
\hline$\Sigma$ & 452 & 42 & 405 & 38 & 210 & 20 & 1067 & 100 \\
\hline
\end{tabular}

Source: authors

The method of electronically questioning and a questionnaire as the principal instrument was applied for researching the Czech enterprises. The phases of the Deming cycle (modified PDCA method) were used to determine the level of selected analytical activities. The questionnaire also included four questions related to the enterprise background: the size of the enterprise measured by the number of employees, the type of the business sector, the company age, and the character of the market by the type of customer (B2B, B2C or both).

${ }^{2}$ The definition of SMEs used in the EU is based on Annex 1 of the Commission Regulation (EU) 651/2014 17. 6. 2014. 
The questionnaire was pre-tested for the instrument validity based on qualitative research through a semi-structured interview with business managers.

The following variables were monitored in the research: evaluation of sales results, customer satisfaction assessment, customer segmentation, customer chum prediction, setting up a method of determining a loyal customer.

The dependent variable increasing companies' profitability was measured by subjective ratings. We asked the respondents to evaluate the increasing companies' profitability, using a five-item, five-point measure adopted for this study (Likert scale). The Cronbach's a of this measure was 0.581 . The mean rating by respondents was 2.2 , with a standard deviation of 1.2 .

The independent variables level of customer satisfaction analysis, evaluation of sales results, customer segmentation, customer churn prediction, setting up a method of determining a loyal customer were measured by subjective indicators included using a five-item, five-point measure adopted for this study (see Deming cycle phase - modification of PDCA method).

Guided by current research and empirical evidence, we have included several control variables. Among the company-level determinants of company performance, the company's size and company age are the two widely used demographic characteristics of companies. Therefore, we include company size (which is measured as the natural logarithm of the number of employees) and company age (in years). We also work with the industry level of the company: whether the company operates in the manufacturing, service sector, or other activities. In addition to these company-level determinants, we also include the type of customer.

\section{Results}

In this part of the article, the formulated hypotheses are verified, and the results of the application of the modified PDCA method in selected analytical activities are evaluated.

\subsection{Impact of selected analytical activities on profitability}

The data obtained from the empirical research on a selected sample of 1067 companies were processed by SPSS. The analysis began by examining the correlation between variables. All variables were screened to reveal their distribution through Pearson correlation coefficients deviations for the variables (Table 2). Table 2 presents the summary statistics of all variables and correlations for the variables. Correlations were obtained from the Pearson Correlations Matrix are shown in Table 2, the values indicating intercorrelations among the predictor's variables ranging from 0.067 to $0.604(p<0.01)$, thus indicating the independence of the variables used for measuring the predictors. Since the descriptive data revealed a promising variation as well as the correlation among the variables included in the model, the results seem to support the hypotheses. The second phase of research includes the analytical method: Hierarchical Regression Analysis. 
Table 2 | Descriptive Statistic

\begin{tabular}{|c|c|c|c|c|c|c|c|c|c|c|c|c|}
\hline & mean & SD & 1 & 2 & 3 & 4 & 5 & 6 & 7 & 8 & 9 & 10 \\
\hline rentability & 1.97 & 0.813 & 1 & & & & & & & & & \\
\hline size & 1.80 & 0.762 & 0.038 & 1 & & & & & & & & \\
\hline age & 2.72 & 0.581 & $-0.168^{\star *}$ & $0.119^{* *}$ & 1 & & & & & & & \\
\hline customer & 2.35 & 0.716 & -0.006 & $0.096^{\star \star}$ & $-0.071^{*}$ & $-0.064^{\star}$ & 1 & & & & & \\
\hline $\begin{array}{l}\text { satisfacti } \\
\text { on }\end{array}$ & 2.20 & 1.129 & $0.071^{\star *}$ & $0.237^{\star \star}$ & 0.044 & $0.100^{\star *}$ & 0.035 & 1 & & & & \\
\hline $\begin{array}{l}\text { segmenta } \\
\text { tion }\end{array}$ & 2.18 & 1.198 & $-0.147^{\star \star}$ & $0.134^{\star \star}$ & $-0.156^{* *}$ & 0.001 & $0.207^{\star \star}$ & $0.548^{* *}$ & $0.494^{* \star}$ & 1 & & \\
\hline churn & 1.20 & 1.424 & $0.115^{*}$ & $0.061^{*}$ & 0.056 & $-0.019^{* *}$ & $-0.225^{\star \star}$ & $0.295^{\star *}$ & $0.395^{\star *}$ & $0.251^{* *}$ & 1 & \\
\hline loyality & 1.73 & 0.675 & $0.234^{\star \star}$ & $0.179^{\star \star}$ & 0.019 & $0.137^{\star \star}$ & $-0.223^{\star *}$ & $0.471^{\star *}$ & $0.325^{\star \star}$ & $0.288^{\star *}$ & $0.604^{\star \star}$ & 1 \\
\hline
\end{tabular}

Note: ${ }^{*} p<0.05 ;{ }^{* *} p<0.01$

Source: authors

Hierarchical regression has been used to test the hypotheses with rentability as of the dependent variable. We tested the impact of satisfaction, sales, segmentation, churn, loyalty, controlling for company size. The results of the analyses are presented in Table 3.

Table 3 | Regression Results for Rentability

\begin{tabular}{lll}
\hline & Model 1 & Model 2 \\
\hline Size & $0.079(0.034)$ & $0.040(0.034)$ \\
Age & $-0.236(0.043)^{\star *}$ & $-0.325(0.043)^{\star *}$ \\
Industry & $0.044(0.030)$ & $-0.001(0.030)$ \\
Customer & $-0.025(0.035)$ & $0.095(0.036)$ \\
Satisfaction analysis H1 & & $0.144(0.028)^{\star *}$ \\
Sales results H2 & & $0.120(0.027)^{\star *}$ \\
Customer segmentation H3 & & $-0.216(0.027)^{\star *}$ \\
Churn prediction H4 & & $0.061(0.019)^{\star *}$ \\
Loyal customer H5 & & $0.298(0.039)^{\star *}$ \\
\hline Model R & & 0.140 \\
$\Delta \mathbf{R}^{2}$ & 0.034 & 0.106 \\
F & 0.034 & $24.630^{\star *}$ \\
Durbin-Watson & $9.405^{\star *}$ & \\
\hline
\end{tabular}

Note: a Unstandardised coefficients are reported, with standard errors in brackets. ${ }^{*} p<0.05$; ${ }^{* *} p<0.01$.

Source: authors 
The multicollinearity test showed that the VIF of independent variables in the final model ranged from 1.003 to 1.704 , and the factor of tolerance range from 0.587 to 0.997 . These values indicate no serious problems with multicollinearity.

We entered the control variables as the first block, Model 1. The regression equation in Model 1 is not statistically significant $(F=0.118, p>0.05)$. The control variables explain $0.0 \%$ of the variance in Model 1 . Model 1 in Table 2 shows that company size is not significantly associated with rentabilities.

The independent variables (satisfaction, sales, segmentation, churn, loyalty) were entered into the regression as the second block, Model 2 . The incremental explanatory prediction on business success was significant in the regression, $\Delta R^{2}$ was 0.140 . The regression equation in Model 2 is statistically significant $(F=24.630, p<0.01)$. The independent variables explain $14.0 \%$ of the variance in Model 2.

Hypothesis 1 claims that there is a positive relationship between the level of implementation of customer satisfaction analysis and increasing profitability. This hypothesis was supported.

Hypothesis 2 claims that there is a relationship between the level of sales evaluation and increasing profitability. This hypothesis was supported.

Hypothesis 3 claims that there is a positive relationship between the level of segmentation of customers and increasing profitability. This hypothesis was supported.

Hypothesis 4 claims that there is a positive relationship between the level of customer churn prediction and increasing profitability. This hypothesis was supported.

Hypothesis 5 claims that there is a positive relationship between the level of setting up a method of determining a loyal customer and increasing profitability. This hypothesis was supported.

Segmentation demonstrates the greatest strength of the impact on the increasing companies profitability, based on the value of the standardized Beta coefficient (Beta $=-0.319$ ), a method for determining loyalty (Beta $=0.248$ ), customer satisfaction analysis (Beta $=0.215$ ), sales results (Beta $=0.170)$ and customer churn prediction (Beta $=0.108$ ). All activities show a positive result, except customer segmentation, which is a surprising finding.

\subsection{Level of selected analytical activities}

Most companies were around the implementation activity level (D), as can be seen in Table 4. The mode is indicated by grey boxes. The mode regarded customer segmentation (43\%), customer satisfaction assessment $54 \%$ ), the evaluation of sales (36\%). The most common response (mode) was also recorded with total inactivity $(\mathrm{W})$, i. e. with customer churn prediction (53\%), as well as the set-up of the loyalty customer method (38\%). This number is even higher when we add to it the companies that are in the planning phase.

Overall, however, we can include all $D+C+A$ phases in the realised analytical parts listed above (see Table 4). These phases differ in the quality of implementation that companies use to further improve customer relationship management. All three activities placed in the first three places (see Table 4) are related together, which indicates a certain degree of integration of the processes in the companies surveyed. 
Table 4 | Results of the analytical part of CRM (in \%) for the whole sample (WPDCA)

\begin{tabular}{lcccccccc}
\hline Activity & W & P & D & C & A & W+P & D+C+A & Order $^{3}$ \\
\hline Evaluation of sales results & 3 & 12 & $\mathbf{3 6}$ & 17 & 32 & 15 & 85 & 1. \\
Customer segmentation & 9 & 13 & $\mathbf{4 3}$ & 17 & 18 & 22 & 78 & 3. \\
$\begin{array}{l}\text { Customer satisfaction assessment } \\
\text { Setting up a method of determining a }\end{array}$ & $\mathbf{3 8}$ & 11 & $\mathbf{5 4}$ & 9 & 20 & 17 & 83 & 2. \\
loyal customer & & & & & & & & \\
Customer churn prediction & $\mathbf{5 3}$ & 6 & 20 & 10 & 11 & 59 & 41 & 5. \\
\hline
\end{tabular}

Source: authors

To summarise the results for the size categories of SMEs, the differences were reflected in the structure of responses between micro, small and medium-sized enterprises in terms of mode (see Table 5).

Table 5 | Response mode in the SME structure

\begin{tabular}{|c|c|c|c|c|c|}
\hline MSP & $\begin{array}{l}\text { Evaluation } \\
\text { of sales } \\
\text { results }\end{array}$ & $\begin{array}{l}\text { Customer } \\
\text { satisfaction } \\
\text { analysis }\end{array}$ & $\begin{array}{l}\text { Customer } \\
\text { segmentation }\end{array}$ & $\begin{array}{l}\text { Customer } \\
\text { churn } \\
\text { prediction }\end{array}$ & $\begin{array}{l}\text { Setting up a } \\
\text { method of } \\
\text { determining } \\
\text { a loyal } \\
\text { customer }\end{array}$ \\
\hline Micro & $\begin{array}{l}31(\mathrm{D}) \\
31(\mathrm{~A})\end{array}$ & $56(\mathrm{D})$ & $32(\mathrm{D})$ & $50(W)$ & $47(W)$ \\
\hline Small & 48 (D) & 50 (D) & $52(\mathrm{D})$ & $58(W)$ & $39(W)$ \\
\hline Medium & $61(\mathrm{~A})$ & 39 (D) & 46 (D) & $48(W)$ & $31(W)$ \\
\hline
\end{tabular}

Source: authors

Let us now have a closer look at how the results for the researched activities differ from implementation from the SMEs structure.

\subsection{Evaluation of sales results}

Most companies (85\%) evaluated sales (Table. 4). Most of these are those (mode) that only carry out this activity, but results are no-verify (D, $36 \%$ ). Non-negligible share is represented by companies that continue to work with the results discovered. $17 \%$ of companies (C) compared the results with the original plan, and even $32 \%(A)$ of companies reached the highest phase of the Deming cycle and adjusted the initial execution of the activity to make a qualitative change from the original plan and use the evaluation to improve customer relationships (see Table 4).

How did different sizes of SMEs tackle this activity? In the case of micro-enterprises, $83 \%$ of the enterprises evaluated sales results. Of this, there were $31 \%$ of enterprises in phase D, $21 \%$ in phase $\mathrm{C}$, and $31 \%$ in the highest phase A. Phase D and phase A are identical in terms of response rates. Overall, $86 \%$ of small businesses evaluated their sales results. Of this, there were $48 \%$ of enterprises in phase D, $21 \%$ in phase C and $17 \%$ in the highest

${ }^{3}$ In terms of implementation. 
phase. The most favourable situation was in the case of medium-sized enterprises, where up to $91 \%$ of them carried out this activity. It was only $24 \%$ in phase D, and $6 \%$ in phase C. Positive is that the mode referred to the highest phase, with up to $61 \%$ of medium-sized businesses (see Figure 2). As companies grow, the share of this activity grows too $(D+C+A)$.

Figure 2 | The level of the evaluation of sales according to the size of enterprises, \% (WPDCA)

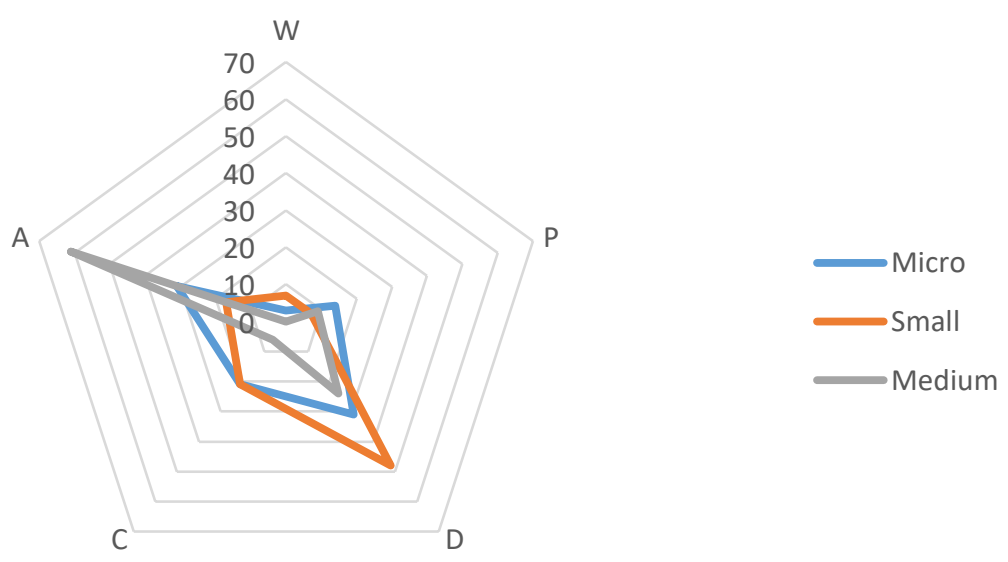

Source: authors

\subsection{Customer satisfaction assessment}

The second place, as can be seen from Table 4. took the analysis of customer satisfaction (83\%). Mode $54 \%$ was in phase D. It was $9 \%$ in phase C, and $20 \%$ in the highest phase (A). What is the situation for the individual size categories of SMEs? In the micro-enterprises, $76 \%$ of the companies performed the analysis of customer satisfaction, $81 \%$ in small companies, and $84 \%$ in medium-sized firms. The proportion of companies that implemented this analytical part of $C R M(D+C+A)$ also grew with a company size category, as was in the case of sales results. For all size categories, D phase dominated. The mode achieved $56 \%$ in micro-enterprises, and it accounted for $50 \%$ in small enterprises. In the medium-sized ones, the model was the lowest, i.e. $39 \%$, but in the highest phase (A) of the Deming cycle were i.e. $36 \%$ (see Figure 3). For micro-sized enterprises, it was $12 \%$ in phase $C$ and $7 \%$ in phase A. For small-sized enterprises, it was $10 \%$ in phase $\mathrm{C}$ and $22 \%$ in phase $\mathrm{A}$. 
Figure 3 | The level of customer satisfaction analysis, \% (WPDCA)

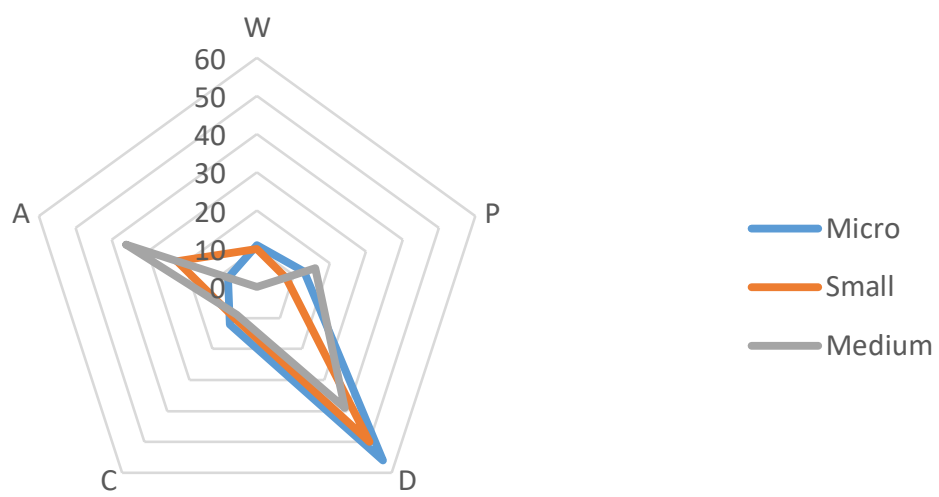

Source: authors

\subsection{Customer segmentation}

Customer segmentation took third place, performed by $78 \%$ of companies (Table 4). The largest share was represented by firms placed in phase D, i.e. $43 \%$. The share of companies at a qualitatively higher level was much lower. In phase $\mathrm{C}$, there were $17 \%$ of companies and $18 \%$ at the highest-level $\mathrm{A}$. When it comes to the results in terms of the size of enterprises, the situation is as follows (see Figure 4). A total of $67 \%$ of microenterprises implemented customer segmentation. In terms of cycle evaluation, the mode concerned phase D (32\%). In phase C, there were $15 \%$ and $20 \%$ in the highest phase A. In total, there were $80 \%$ of small enterprises performing customer segmentation. Phase $\mathrm{D}$ was confirmed by most companies (52\%). Phase $\mathrm{C}$ was identified by $17 \%$ of companies, and there were only $11 \%$ in the highest phase A. What was the situation with medium-sized businesses like? In phase $\mathrm{D}$, there were $46 \%$ of companies. There were $16 \%$ in phase C. Almost one-third of companies confirmed the highest phase A (29\%). Overall, it was $91 \%$. Even with this activity, the results confirm that the proportion of the realisation of customer segmentation $(D+C+A)$ increases with the size of the company.

Figure 4 | The level of customer segmentation according to the size of enterprises, \% (WPDCA)

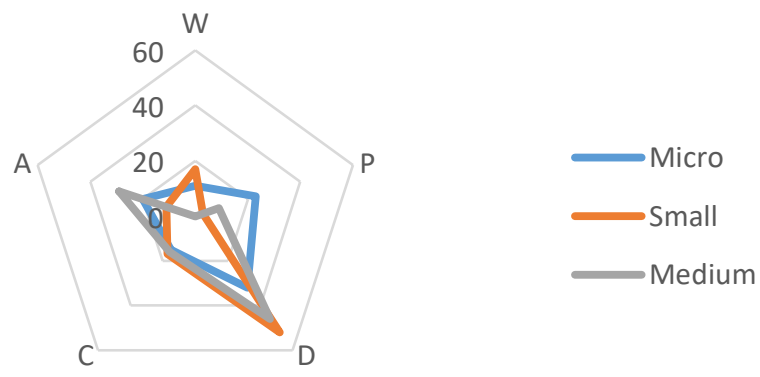




\subsection{Setting up a method of determining a loyal customer}

In total, $46 \%$ of companies performed the analysis of customer loyalty (see Table 4). In phase D, $27 \%$ of enterprises performed it. In phase C, $11 \%$ and phase A $8 \%$ of enterprises. $54 \%$ of the companies were in $\mathrm{W}+\mathrm{P}$ phases, which means that this activity was not implemented (see Tab. 4). Concerning the results by size categories, respondents responded as follows: only $37 \%$ of micro-enterprises carried out the surveyed activity $(D+C+A), 46 \%$ of smallsized enterprises and $53 \%$ of middle-sized enterprises. The mode was found in phase W. If we look at the implementation of the activity in terms of the individual phases, then the most micro-enterprises, i.e. $19 \%$, were in phase D, $14 \%$ in phase C, and only $4 \%$ in the highest phase. Small enterprises were slightly better in phase D, accounting for $36 \%$ of enterprises. In phase $\mathrm{C}$, it was only $3 \%$ and $7 \%$ in the highest phase. The quality of the analysis of customer loyalty was highest in medium-sized enterprises. The dividing of responses by cycle phase was more balanced. It was $24 \%$ in phase D, $16 \%$ in phase C and $13 \%$ in the highest phase (see Figure 6).

Figure 6 | The level of setting up the method of determining a loyal customer, \% (WPDCA)

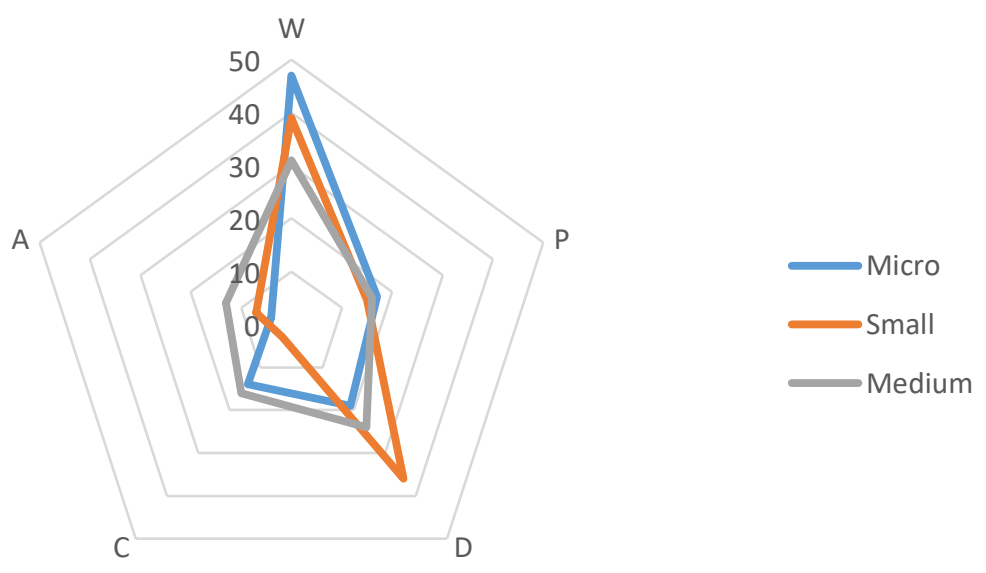

Source: authors

\subsection{Customer churn prediction}

Let us also pay attention to activities that are not the focus of SMEs. More than half of the companies $(59 \%)$ do not perform this activity $(\mathrm{W}+\mathrm{P})$. The mode can be monitored in phase W $(53 \%), 6 \%(P)$ plan this activity. In the implementation phases $(D+C+A)$, the most frequent response was phase D (20\%), $10 \%$ in phase C, and only $11 \%$ of companies were in the highest phase $\mathrm{A}$ (see Table 4).

Of the micro-enterprises, $37 \%$ of the companies applied customer churn prediction. Approximately $42 \%$ of small-sized enterprises also performed customer churn prediction; however, in the case of medium-sized enterprises, it was $52 \%$, which was the most. How did the size categories look like in detail? A tenth of microenterprises was in phase D. Nearly a quarter $(23 \%$ ) reported phase $\mathrm{C}$. At the peak of cycle, A, there were only $4 \%$ of companies. 
Half of the micro-enterprises (mode) did not implement the prediction at all (W). $13 \%$ were only in the planning phase of this activity $(\mathrm{P})$. Most of the small companies were in phase $\mathrm{D}$ (28\%), only $3 \%$ were in phase C, and in the highest phase A, it was $11 \%$. However, the mode pertained to phase W (58\%), which was even higher than for micro-enterprises. There was not even one small business in the planning phase. As far as medium-sized enterprises are concerned, the number of companies performing customer churn prediction was higher than for micro and small enterprises. In phase D, there were $30 \%$ of companies, in phase $\mathrm{C}$ $0 \%$ and phase A $22 \%$. Even in the case of medium-sized enterprises, the mode concerned inactivity W (48\%). No enterprises have planned this activity. The situation for all size categories can be seen in the graph in Figure 5.

Figure 5 | The level of customer churn prediction, \% (WPDCA)

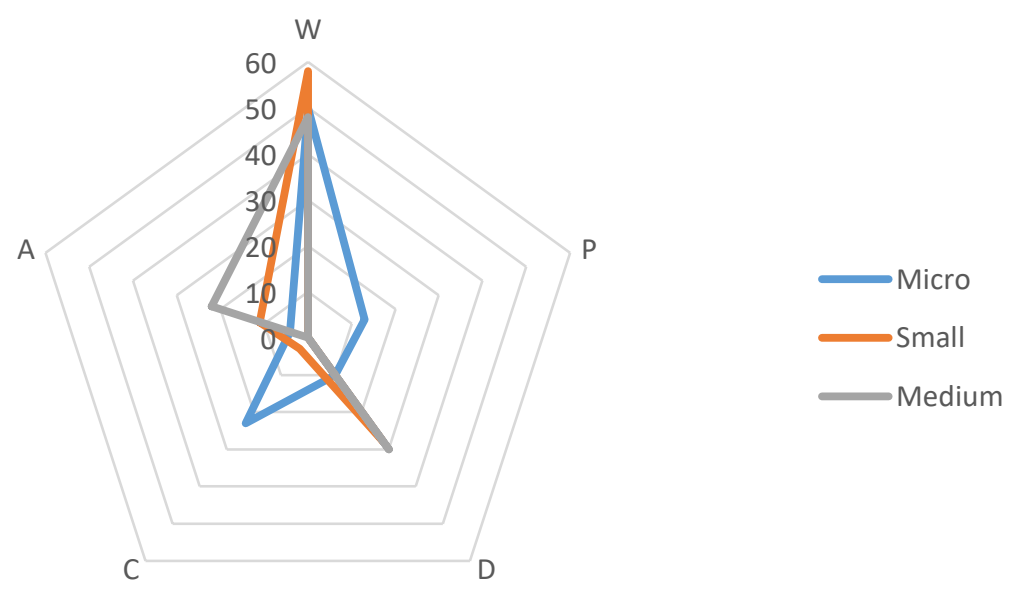

Source: authors

\section{Discussion}

Selected analytical activities are related and complementary to each other. All of them showed an effect on the companies' profitability in the sample. However, the application of the modified PDCA method (WPDCA) has shown a different level of implementation.

Sales analysis, customer satisfaction, and customer segmentation showed the best results in terms of their implementation. The issue of customer loyalty and customer churn prediction was in the last position. The researched companies confirmed that they are better at performing basic marketing activities. The level of activities on which successful CRM is based was lower.

The implementation of activity (phase $\mathrm{D}$ ) does not take place in an isolated form. It should be based on a plan that aims to make changes to the CRM implementation process in the company and to eliminate the causes of problems. Increasing customer awareness will lead to an understanding of their needs and the growth of their satisfaction, which can be reflected in extending customer relationships and consolidating their loyalty. These positive changes 
in processes also affect sales growth and an overall improvement in economic performance. This positive development then eliminates customer churn for competitors. Various schemes and standardised methodological approaches to performing activities or flow diagrams, etc., can be used in this phase (Janusiak-Kocik, 2017).

Tracking sales results took the first place, but that's not enough. The monitoring of sales results is not enough. This activity is already carried out by companies in their pioneering phase of organisational development. It is important to use sales results for customer relationship management and to define the value of individual customers, and formulate a strategy for attracting and retaining profitable customers, as mentioned in the theoretical part. The share of this activity is the highest in the sample $(D+C+A: 85 \%)$. The mode was in phase $\mathrm{D}(36 \%)$. A positive phenomenon is also that in the qualitatively highest phase $A$, there are only 4.p.b fewer respondents. This means that companies will benefit from these analytical sales results for qualitative process changes within the CRM system. The results application can contribute to a more accurate estimation of the customer's value. According to Loštáková (2009), companies can use customer value to differentiate the approach to customer relationship management. This enables the creation of a customer's portfolio according to their benefits over time. The consulting firm Deloitte emphasises that the customer has more value than the amount he/she spent in the company. He/she can return and report to others. ${ }^{4}$

A high share of our respondents $(D+C+A: 83 \%)$ confirmed that they are doing customer satisfaction analyses. It is known that in quality management, some ISO standards require monitoring of customer satisfaction. The mode was in phase D (54\%), which was even higher than in the case of sales analysis. In the highest phase, the share was only one-fifth, which is not so positive anymore because enterprises make little use of the opportunity to improve and develop this analysis in practice.

A study of the Shell company showed that customer relationship management has an impact on customer satisfaction (Hassan et al., 2015). The customer will be more satisfied with a company that implements thoughtful and reliable customer relationships. The study concludes that CRM plays a significant role in increasing market share, positively influences employee productivity and morale. It improves customer awareness and satisfaction, which leads to improved customer loyalty. In practice, however, even a dissatisfied customer can be loyal if he has no alternative. However, this does not happen very often in a competitive market. Customer Satisfaction Analysis provides information on customer needs and allows us to understand what needs to be done to make customers even more satisfied. Although the research in the Shell company was not carried out in SMEs, still it shows the need to analyse satisfaction in all enterprises that want to be successful in the market. Confidence also affects customer satisfaction.

Also, Blažková (2016), who deals with SME marketing, combines customer churn with their satisfaction. High satisfaction is reflected in higher purchases, lower price sensitivity, or transaction costs. It increases customer loyalty. Customers help spread the company's reputation and offer suggestions for new products and services. Behavioural loyalty can be assessed according to customer purchases, according to his activities, stability of expenses, and also according to his attitudes and emotional perception. Opinions on the relationship

\footnotetext{
${ }^{4}$ Web portal Deloitte. Customer retention. [online]. [see 16. 11. 2019]. Available at: https://www2.deloitte.com/cz/cs/pages/deloitte-analytics/solutions/advanced-customer-retention.html
} 
between customer satisfaction and repeat purchases are not uniform, as Paulsen and Birk (2007).

According to Buttle and Maklan (2015), those customers who are more strongly involved are more loyal. Enterprises can carry out customer satisfaction research in different ways. It depends on their financial possibilities, whether they carry out research themselves or use the services of consulting companies. For SMEs, the financial side is limiting (Ajmera, 2013). Then it is possible to choose even fewer demanding surveys, mystery shopping, short surveys at the point of sale or books of wishes and complaints to find out about customers feedback.

Already earlier, the link between sales evaluation and customer value, profitability, and differentiated customer relationship management has been highlighted. The customer division into target groups and segments is the basis for marketing mixes. It is easier to understand the needs of customers and to adapt the offer of products and services, price offers, a form of distribution, and marketing communication. All this contributes to better company results and higher customer satisfaction. Customer segmentation ranked in our research. Third, $78 \%(D+C+A)$ of respondents confirmed it. The largest share was represented by enterprises placed in phase D, i.e. $43 \%$. The qualitatively higher phases reached relatively small shares, which did not even reach $20 \%$, and is similar to customer satisfaction assessment. Customer segmentation is based on various criteria. The study by Srivastava et al. (2002) points out that each customer segment brings different profit. Segmentation thus reveals key (significant) customers. The term key customer is not unified in the literature. The literature offers more approaches to sorting.

A negative situation was also in the case of evaluation of customer loyalty. This activity was in the penultimate place. The mode was in phase W (38\%). Overall, up to $54 \%(\mathrm{~W}+\mathrm{P})$ of respondents do not carry out this activity, even taking into account phase $P$. Customer loyal assessment makes it possible to indicate the risk of customer outflow, to which companies can respond appropriately by appropriate measures. It is very vital for companies to create a loyal customer base. If it lasts for a long time, it is one of the best ads to help create a highquality image. This helps to attract more customers who appreciate long-term relationships and high-quality products and services. "Event marketing" can also be used to promote loyalty. These actions can copy events in the life of the customer (Srivastava et al., 2002). For instance, this can be a birthday congratulation. This is a low-cost and high-efficiency event.

According to Cheverton (2008), it is a customer that enterprises must not lose because it has great sales potential and helps the company meet its goals. Companies can lose customers for various reasons. Loštáková (2009) points out that it can also be profitable customers who are leaving. In this case, companies would like these customers to return. In most cases, however, these are customers who have some negative experience with the company. They were, for example, poorly serviced, dissatisfied, and had a low loyalty to the company. Most of our respondents do not investigate the causes of customer churn prediction. The mode was in phase W (53\%). Overall, $59 \%(\mathrm{~W}+\mathrm{P})$ of respondents did not carry out this activity and do not even plan it for the future. In terms of implementation, this activity was in the last position, which is not a positive finding. According to the consulting company Deloitte, which also deals with the outflow of customers in companies, some enterprises are not able to evaluate how many customers lose each year and how much money it costs. Companies do 
not investigate to research the causes of customers outflow. The possibility of using the services of consulting companies is limited by SMEs' financial sources. One of the most important motives for customers outflow is competition. Customer retention and related loyalty are influenced by their satisfaction.

The research results showed that the share of implemented activities $(D+C+A)$ increases with the size of SMEs. The highest share is reached by medium-sized enterprises, which already show some form of division of labour and specialisation of functions of professional employees, which can include also marketing employees, who are mainly in charge of customers. Many successful companies perceive the customer relationship holistically, which means that they may not even have a marketing department but are all customer-oriented and think "marketing-wise" within the company. On the other hand, the impact of the size category of SMEs on the profitability of companies has not been proven. Even a microenterprise with a well-developed approach to customer relationship management can gain the economic effect of its work.

The research results are limited by the fact that the object of the research was only companies from the Moravian-Silesian region. A certain limitation was that it was the SMEs, although we tried not only to evaluate the whole sample but also the answers in terms of size categories of SMEs. Within the implementation of the questionnaire research, the research team struggled with a lack of interest in cooperation and, to some extent, with ignorance on the part of the respondents, which was reflected in the incomplete respondents' answers and the subsequent request of questionnaires from the research.

The direction of further research should be geared to further assessing the relationship between activities to search for methods to improve the quality of processes and activities within the CRM architecture and to formulate recommendations for SMEs that can overall strengthen their competitiveness and market position. The research will focus on other parts of the CRM architecture, namely, strategic, operational, and collaborative. Subsequent research could provide a comparison in the development of the level of research activities and individual phases of the Deming cycle and identify the development trend. In the area of analytical activities, it would be possible to further explore the individual subsegments of SMEs concerning the selection of analytical tools for micro, small and medium-sized enterprises, which do not represent a homogeneous set in terms of organisation and approaches to business and CRM. The research results presented in this article reveal further possibilities for subsequent research.

\section{Conclusion}

The aim of the article was to evaluate the level of the analytical part of CRM processes in small and medium enterprises in the Czech Republic and its impact on increasing the companies profitability. This article attempts to provide a new perspective on CRM level assessment. The starting point was the Anglo-Australian approach to relationship marketing, which includes customer relationship management.

A modified PDCA method was used to assess this level. Johnson (2002) states that the PDCA method is a well-known model for continuous improvement of processes. The evaluation of the individual phases of the cycle was carried out according to the mode. The evaluation of the level of individual activities was summarised according to the share of 
realised $(D+C+A)$ and unrealised activities $(W+P)$ and according to the model in the individual phases of the Deming cycle. This approach pointed to the highest level in the case of the evaluation of sales (85\%), customer satisfaction (83\%), and customer segmentation (78\%). The lowest level was reflected in the set-up of customer loyalty measurement (46\%) and customer churn prediction (41\%). The last two mentioned analytical activities were not performed by more than half of the companies, which is a very important activity for CRM success, which determines the building of long-term relationships with customers. There are differences between the individual phases with the different categories of enterprises. Most respondents had a mode in the implementation phase (D). The only exception was the analysis of sales results for micro and medium-sized enterprises, which was in the highest phase. A typical show of the research of individual phases of the Deming cycle was the growth of the shares of implemented activities with the growth of the companies size, which may be a reflection of a more sophisticated organisation and CRM process in these size categories. All analytical research activities showed the effect of increasing the company's profitability. Dependence was proved for all variables, although the correlation coefficient $R$ is low, and the regression relationship is not strong.

How can the results of our research be inspiring for entrepreneurs? The practical use may be to apply the PDCA method (WPDCA) to evaluate the quality of their own CRM processes. It will help companies evaluate the level of activities and individual phases. The analytical part of CRM can provide knowledge on how to connect all parts of the CRM architecture. Repeated and systematic evaluation, which is the principle of the Deming cycle, can highlight the necessary changes to improve these processes and respond flexibly to the changing business environment.

\section{Acknowledgement}

The article was prepared based on research conducted in the context of ensuring the sustainability of the student grant competition project SGS/7/2017: "Acceptance of technology from the perspective of marketing tools."

\section{References}

Ajmera, J. (2013). A CRM system for social media: challenges and experiences. In H. Ahn, M. Nagarajan, A. Verma \& D. Contractor. New York: ACM, 49-58. https://dl.acm.org/doi/pdf/10.1145/2488388.2488394.

Alshawi, S., Missi, F., \& Irani, Z. (2011). Organisational, technical and data quality factors in CRM adoption—SMEs perspective. Industrial Marketing Management, 40(3), 376-383.

Blažková, I. (2016). The impact of the public support for R\&D on the economic performance of SMEs. Acta Universitatis Africulturae et Silviculturae Mendelianae Brunensis, 4(1), 213-222. https://doi.org/10.11118/actaun201664010213.

Burnett, K. (2002). Key customers and care for them. Praha: Computer Press.

Buttle, F., \& Maklan, S. (2015). Customer relationship management: concepts and technologies. Routledge, Taylor and Francis Group, London, U.K.

Day, G. S., \& Wensley, R. (1983). Marketing theory with strategic orientation. Journal of Marketing, 47(4), 79-89. https://doi.org/10.2307/1251401.

Dohnal, J. (2002). Customer relationship management. Prague: Grada Publishing. 
Doyle, P. (2000). Value-Based Marketing. New York: John Wiley \& Sons.

Hassan, R., Nawaz, A., \& Lashari, S. A. (2015). Effect of Customer Relationship Management on Customer Satisfaction. In D. F. Zafar (Eds), Procedia Economics and Finance, 23(15), 563-567. https://doi.org/10.1016/S2212-5671(15)00513-4.

Gupta, P. (2006). Beyond PDCA-A New Process Management Model. Quality Progress, 39(7), 45-52.

Godson, M. (2009). Relationship Marketing. New York: Oxford University Press.

Greenberg, P. (2010). The impact of CRM 2.0 on customer insight. Journal of Business and Industrial Marketing, 25(6), 410-419. https://doi.org/10.1108/08858621011066008.

Chen, I. J., \& Popovich, K. (2002). Understanding customer relationship management (CRM) People, process and technology. Business process management journal, 9(5), 672-688. https://doi.org/10.1108/14637150310496758.

Cheverton, P. (2008). Key Account Management: Tools and Techniques for achieving profitable key supplier status. 4th Edition. Great Britain: MPG Book Ltd.

Christopher, M., Payne, A., \& Ballantyne, D. (1991). Relationship Marketing. Oxford: ButterworthHeinemann.

Chromčáková, A., Starzyczná, H., \& Klepek, M. (2018). The measurement methods of customer value and its use in small and medium sized Czech enteprises. Papers of the University of Pardubice, Series D., 4(2), 87-99.

Jakubíková, D. (2013). Strategic marketing - strategies and trends. Praha: Grada Publishing.

Janusiak-Kocik, M. (2017). PDCA cycle as a part of continuous improvement in the production company - a case study. Production Engineering, 14(1), 19-22.

Johnson, C. N. (2002). The benefits of PDCA. Quality Progress. 35(5), 120.

Khalafinezhad, R., \& Long, C. S. (2013). Customer Satisfaction and Loyalty: A Review in the Perspective of CRM. Journal of Technology, 64(2), 61-66. https://doi.org/10.11113/jt.v64.2237.

Kmieciak, R. (2010). Systemy CRM a funkcjonowanie małych i średnich przedsiębiorstw w dotychczasowych badaniach empirycznych. W: R. Knosala (red.), Komputerowo zintegrowane zarządzanie. T. 1, Opole: Oficyna Wydawnicza Polskiego Towarzystwa Zarządzania Produkcją.

Knop, K., \& Mielczarek, K. (2015). The improvement on the basis of PDCA and SDCA cycles. Quality Improvement Practice in Different Branches, 2(3), 60-71.

Kotler, P., \& Keller, K.L. (2013). Marketing and management. Praha: Grada Publishing.

Kotler, P., Kartajaya, H., \& Setiawan, I. (2016). Marketing 4.0: Moving from Traditional to Digital. Viley.

Kozel, R., Mynářová, L., \& Svobodová, H. (2011). Moderní metody a techniky marketingového výzkumu. Praha: Grada Publishing.

Levitt, T. (1960). Marketing Myopia. Harvard Business Review, 38(2), 45-60.

Liagkouras, K., \& Metaxiotis, K. (2014). Application of Customer Relationship Management Systems in Business: Challenges and Opportunities. International Journal of Computer and Information Engineering, 8(6), 1642-1646.

Loh, B. K., Koo, K. L., Ho, K. F., \& Idrus, R. (2011). A review of customer relationship management system benefits and implementation in small and medium enterprises. Mathematics and Computers in Biology, Business and Acoustics, 12th WSEAS International Congference on 
Mathematics and Computers in Biology and Chemistry, Transilvania, University of Brasov, Romania.

Loštáková, H. (2009). Differentiated customer relationship management. Praha: Grada Publishing.

Loštáková, H. (2017). Tools for strengthening customer relations in the B2B market. Praha: Grada Publishing.

Marquis, R. (2009). How to Roll the Deming Wheel. DITY Weekly Newsletter, 5(28), 1-3.

Miklenčičová, R. (2012). Meranie ukazatelov výkonnosti CRM. Trnava: Univerzita sv. Cyrila a metoda v Trnave. Fakulta masmediálnej komunikácie.

Niraj, R., Gupta, M., \& Narasimhan, C. (2001). Customer Profitability in a Supply Chain. Journal of Marketing, 65(7), 1-16.

Paulsen, M. \& Birk, M. (2007). Satisfaction and Repurchase Behavior in a Business-to-Business Setting: Investigating the Moderating Effect of Manufacturer, Company and Demographic Characteristics. Industrial Marketing Management, 36(7), 983-997. https://doi.org/10.1016/j.indmarman.2007.05.011

Peelen, E. (2005). Customer Relationship Management. Essex: Pearson Education Limited.

Piskar, F. (2009). A Successful CRM Implementation Project in a Service Company: Case Study. In A. Faganel. (Ed). Organizacija, 42(5), 199-208.

Rai, A. K. (2013). Customer relationship management: Concepts and cases. New Delhi: PHI Learning.

Reicher, R., \& Szeghegyi, Á. (2015). Factors Affecting the Selection and Implementation of a Customer Relationship Management (CRM). Acta Polytechnika Hungarica, 12(4), 183-200.

Reinartz, W., Thomas, J. S., \& Kumar, V. (2005). Balancing acquisition and retention resources to maximise customer profitability. Journal of Marketing, 69(1), 63-79.

Ralston, R. W. (2003). The effects of customer service, branding, and price on the perceived value of local telephone service. Journal of Business Research, 56(3), 201-213. https://doi.org/10.1016/S0148-2963(01)00221-1.

Rust, R. T., Ambler, T., \& Gregory, S. C. (2004). Measuring Marketing Productivity: Current Knowledge and Future Directions. In V. Kumar \& R. K. Srivastava (Eds). Journal of Marketing, 68(10), $76-$ 89. https://doi.org/10.1509/jmkg.68.4.76.42721.

Shewhart, W. A. (1939). Application of statistical method in mass production. In Proceedings of the Industrial Statistics Conference Held at Massachusetts Institute of Technology, September 8-9. Pitman Publishing Corporation, New York.

Srivastava, J., Wang, J. H., \& Lim, E. P. (2002). A Case for Analytical Customer Relationship Management. In S. Y. Hwang (Eds). Computer Science \& Engineering, 14-27. https://doi.org/10.1007/3-540-47887-6_3.

Starzyczná, H., Kauerová, L., \& Pellešová, P. (2007). Methodology of relationship marketing and its position in strategic marketing and customer relationship management (CRM) - practical use. Karviná: SU OPF.

Starzyczná, H., Stoklasa, M. \& Pellešová, P. (2016). CRM and its results in Czech small and medium companies. 9th International Scientific Conference Business and Management.

Tsiros, M., Mittal, V., \& Ross, W. T. (2004). The role of Attributions in Customer Satisfaction: A Reexamination. Journal of Consumer research, 31(2), 476-483. https://doi.org/10.1086/422124.

Vávrová, V. (2016). The way to create customer value. Marketing a komunikace, 26(2-3), 11-14. 
Verhoef, P. C., \& Lemon, K. N. (2013). Successful customer value management: Key lessons and emerging trends. European Management Journal, 31(1), 1-16. https://doi.org/10.1016/j.emj.2012.08.001.

Xie, Y., Li, X., \& Ying, W. (2008). A Process Driven Architecture of Analytical CRM Systems with Implementation in Bank Industry. International Journal of Intelligent Information Technology Application, 1(1), 48-52. https://doi.org/10.1109/CCCM.2008.307.

The research paper passed the review process. | Received: July 6, 2020; Revised: September 3, 2020; Accepted: September 14, 2020; Pre-published online: January 29, 2021; Published in the regular issue: July 2, 2021. 